\title{
Lamellar body ultrastructure revisited: high-pressure freezing and cryo-electron microscopy of vitreous sections
}

\author{
Dimitri Vanhecke · Gudrun Herrmann • \\ Werner Graber · Therese Hillmann-Marti • \\ Christian Mühlfeld · Daniel Studer · Matthias Ochs
}

Accepted: 17 August 2010 / Published online: 1 September 2010

(C) Springer-Verlag 2010

\begin{abstract}
Lamellar bodies are the storage sites for lung surfactant within type II alveolar epithelial cells. The structure-function models of lamellar bodies are based on microscopic analyses of chemically fixed tissue. Despite available alternative fixation methods that are less prone to artifacts, such as cryofixation by high-pressure freezing, the nature of the lung, being mostly air filled, makes it difficult to take advantage of these improved methods. In this paper, we propose a new approach and show for the first time the ultrastructure of intracellular lamellar bodies based on cryoelectron microscopy of vitreous sections in the range of nanometer resolution. Thus, unspoiled by chemical fixation, dehydration and contrasting agents, a close to native structure is revealed. Our approach uses perfluorocarbon to substitute the air in the alveoli. Lung tissue was subsequently high-pressure frozen, cryosectioned and observed in a cryoelectron microscope. The lamellar bodies clearly show a tight lamellar morphology. The periodicity of these lamellae
\end{abstract}

D. Vanhecke and G. Herrmann contributed equally to this study.

D. Vanhecke · G. Herrmann · W. Graber · T. Hillmann-Marti ·

D. Studer · M. Ochs

Institute of Anatomy, University of Bern, Bern, Switzerland

D. Vanhecke $(\bowtie)$

Department of Molecular Structural Biology,

Max Planck Institute of Biochemistry,

Martinsried, Germany

e-mail: vanhecke@biochem.mpg.de

C. Mühlfeld

Institute of Anatomy and Cell Biology,

Justus-Liebig-University Giessen, Giessen, Germany

M. Ochs

Institute of Functional and Applied Anatomy,

Hannover Medical School, Hannover, Germany was $7.3 \mathrm{~nm}$. Lamellar bifurcations were observed in our cryosections. The technical approach described in this paper allows the examination of the native cellular ultrastructure of the surfactant system under near in vivo conditions, and therefore opens up prospectives for scrutinizing various theories of lamellar body biogenesis, exocytosis and recycling.

Keywords Lung · Lamellar body · Surfactant . High-pressure freezing $\cdot$ CEMOVIS

\section{Introduction}

Lung surfactant is a complex mixture of proteins and lipids, mainly saturated phospholipids such as dipalmitoylphosphatidylcholine (DPPC), which act together as a highly surface-active substance with the ability to reduce surface tension along the alveolar epithelium to prevent the collapse of alveoli. Additionally, surfactant components are known to be involved in pulmonary host defense (Clements 1997; Wright 1997, 2005; Wright et al. 2001).

The components of surfactant are produced in type II alveolar epithelial cells (Mason and Williams 1977; Fehrenbach 2001). The surfactant protein components are synthesized in the endoplasmic reticulum, processed in the Golgi apparatus and partly packaged in intracellular storage organelles known as lamellar bodies (Kikkawa et al. 1965; Sorokin 1967; Kuhn 1968; Askin and Kuhn 1971; for review, see Weaver et al. 2002; Ochs 2010). In a poorly understood process, cytoplasmic phospholipids are actively transported through the limiting membrane of the lamellar body. In mice, the average type II cell contains 50-100 lamellar bodies of 0.2-2 $\mu \mathrm{m}$ diameter each (Ochs et al. 2004).

The ultrastructural model of lamellar bodies was worked out mainly between 1970 and 1990. Lamellar bodies 
appeared in ultrathin sections of chemically fixed and epoxy resin-embedded cells as osmiophilic vesicles with tightly packed, more or less periodically arranged lamellae. The lamellae were surrounded by an outer limiting membrane, provided lipid-retention protocols were applied (Douglas et al. 1975). The observation of lamellae and their periodicity depend on the chemicals used (Stratton 1977). The use of heavy metal salts containing osmium or uranium (Collet 1979; Ikeda et al. 1984) offers, generally considered, the best results despite the fact that osmotic shock and swelling artifacts are known to arise from osmium treatment (Hayat 2000).

Physical fixation avoids the use of aldehyde fixatives. The sample is immobilized by quick cooling within a time period of about $60 \mathrm{~ms}$ (Studer et al. 1995). Unless the sample is cryosectioned, dehydration steps are still required for transmission electron microscopy. In the case of freeze drying, the dehydration step is performed through sublimation without the use of solvents. However, staining procedures based on osmium are upheld to improve the contrast of the osmiophilic lamellar bodies (McAteer and Terracio 1984; Terracio et al. 1981). Empty vacuolar structures were found in non-osmificated freeze-dried samples, but no lamellar bodies (Yang et al. 2006). Freeze substitution comprises a dehydration procedure in organic solvents at low temperatures (around $-90^{\circ} \mathrm{C}$ ). Yet again, only tissue treated with osmium resulted in well-preserved lamellar bodies (Ikeda et al. 1984). Freeze fracturing, a preparation method particularly useful for examining lipid membranes and thus ideal in the case of lamellar bodies, has been used on several occasions and helped considerably in obtaining a better understanding of the lamellar body morphology (Kikkawa and Manabe 1978; Smith et al. 1972; Takemura et al. 1987; Williams 1978). A metal replica of the cryofixed sample/ freeze fractured tissue is made, eliminating the necessity for osmification, dehydration or embedding. Although theoretically not required, the need for chemical fixation often remains in practice: specimens not stabilized by chemical fixatives tend to be rather soft and the replicas break during cleaning procedures (Schulz et al. 1980). Moreover, the limited heat conductivity of water forces the use of cryoprotectant infiltration to avoid tissue damage due to formation of ice crystals (Willison and Rowe 1980). These cryoprotectants, usually glycerol, introduce a variety of physiological and structural changes including rearrangements of lipids in membranes (Costello and Gulikkrzywicki 1976; Niedermeyer et al. 1977). Attempts to cool down bulk samples in the absence of both chemical fixation and cryoprotection treatment suffered from ice crystal damage (Untersee et al. 1971): quick freezing at ambient pressure cannot provide bulk samples (Sartori et al. 1993; Shimoni and Muller 1998; Studer et al. 1995) and ice crystal formation occurs in a typical biological sample at a depth of about $20 \mu \mathrm{m}$ (Escaig 1982). In spite of these technical difficulties, platinum-coated plunge-frozen lung tissue could be observed in the cryo-scanning electron microscope without the use of chemical fixatives, cryoprotectants or solvents (Bastacky et al. 1995), but only in the outermost wall of immediately subpleural alveoli and only up to a depth of $5 \mu \mathrm{m}$ (Lee and Bastacky 1995).

The idea for cryo-electron microscopy of frozen hydrated sections of lung tissue was proposed to avoid chemical fixation, dehydration, cryoprotectants and staining procedures (Kawanami and Lauweryns 1977). The contrast reflects biological distribution rather than osmium affinity (Dubochet et al. 2007). Unfortunately, this technique now known as CEMOVIS (cryo-electron microscopy of vitreous sections; Al-Amoudi et al. 2004b; Dubochet et al. 1988) was not yet fully developed, and Kawanami and Lauweryns (1977) required a mild chemical fixation prior to cryofixation to be able to produce sections.

In this paper, the high-pressure freezing approach (Muhlfeld et al. 2007) is further developed: an attempt to circumvent the alveolar collapse is made by total liquid ventilation prior to fixation. High-pressure freezing combined with CEMOVIS allows for the observation of hydrated biological samples with a biological contrast distribution at the ultrastructural level. Ultrastructural information without the use of any chemical fixatives, cryoprotectants, dehydration solvents or staining procedures is provided. Ice crystal-free samples of bulk lung tissue up to $200 \mu \mathrm{m}$ thickness containing alveolar epithelial type II cells could be obtained by means of high-pressure freezing combined with CEMOVIS.

\section{Materials and methods}

\section{Animals}

Adult BALB/c mice were used for this study. Mice were kept on a 24-h day-night cycle with food and water ad libitum. All experiments were performed in accordance with the international guidelines for ethical animal research and were approved by the local committee of Canton Berne, Switzerland.

For comparative purposes, samples from the perfluorocarbon treatment were divided into three groups, namely, Group A: chemically fixed (chemical fixatives, solventbased dehydration and osmification at room temperature); Group B: high-pressure frozen and freeze substituted (cryofixation, solvent-based dehydration and osmification at low temperatures); Group C: cryo-electron microscopy of frozen hydrated sections (high-pressure freezing, cryo-ultramicrotomy followed by cryo-electron microscopy). 
Conventional transmission electron microscopy

Fixation and processing were carried out as described in detail earlier (Fehrenbach and Ochs 1998; Muhlfeld et al. 2007). Briefly, mice lungs were fixed by instillation with a mixture of $1.5 \%$ glutaraldehyde $1.5 \%$ formaldehyde (from freshly depolymerized paraformaldehyde) in $0.15 \mathrm{M}$ Hepes buffer. Lung tissue blocks were postfixed for $2 \mathrm{~h}$ in $1 \%$ $\mathrm{OsO}_{4}$ in $0.1 \mathrm{M}$ cacodylate buffer and stained en bloc overnight $(12-18 \mathrm{~h})$ at $4-8^{\circ} \mathrm{C}$ with half-saturated aqueous uranyl acetate. The specimens were dehydrated in a series of acetone/Epon solutions and finally embedded in Epon. Ultrathin $(\sim 50 \mathrm{~nm})$ sections were cut and contrasted with lead citrate and uranyl acetate.

\section{High-pressure cryofixation}

Mice were deeply anesthetized by a subcutaneous injection (300 $\mu \mathrm{l} / 100 \mathrm{~g}$ body weight) of a mixture of fentanyl $(0.05 \mathrm{mg} / \mathrm{ml})$, midazolam $(5 \mathrm{mg} / \mathrm{ml})$ and medetomidin ( $1 \mathrm{mg} / \mathrm{ml}$ ). Mice were brought into total liquid ventilation using warmed $\left(37^{\circ} \mathrm{C}\right)$ and oxygenated perfluorocarbon (Fluorinert ${ }^{\mathrm{TM}}$ FC-77, $3 \mathrm{M}$, Zwijndrecht, Belgium) to substitute the air in the alveoli. The animals were subsequently killed by an overdose of pentobarbital $(150 \mathrm{mg} / \mathrm{kg})$. The thorax was opened and the lungs exposed. Still filled with perfluorocarbon, small pieces of lung tissue were excised and locked in a dedicated platelet for high-pressure freezing in an EMPACT-RTS2 high-pressure freezer (Leica-Microsystems, Vienna, Austria) operating at 2,048 bar. To fit the platelet, the tissue pieces were about $1 \mathrm{~mm}$ in diameter and about $0.2 \mathrm{~mm}$ thick. The procedure was performed as fast as possible to avoid any autolytic processes prior to cryofixation (Studer et al. 2001; Vanhecke et al. 2006; Vanhecke et al. 2003). Typically, from excision of the tissue to finalization of the fixation took about $30 \mathrm{~s}$. After cryofixation, the samples were kept in the platelets at $-196^{\circ} \mathrm{C}$. The last tissue sample was high-pressure frozen within $30 \mathrm{~min}$ after the onset of liquid ventilation.

Freeze substitution

The freeze-substitution medium consisted of dehydrated acetone containing $2.5 \%$ osmium tetroxide and $2 \%$ uranyl acetate for Epon embedding. The embedding was carried out in the Eppendorf system of an AFS freeze-substitution machine (Leica) at $-90^{\circ} \mathrm{C}$ as described earlier (Vanhecke et al. 2006).

\section{CEMOVIS}

Frozen hydrated sections of high-pressure frozen lung tissue were obtained with a cryo-ultramicrotome FCS (Leica)
(Al-Amoudi et al. 2004a). The working temperature of the knife, sample holder and chamber atmosphere were adjusted to $-160^{\circ} \mathrm{C}$. The samples were glued to a pin with cryoglue (Richter 1994) and then trimmed with a $35^{\circ}$ diamond knife (Diatome, Biel, Switzerland). The obtained frozen hydrated sections were placed on 200 mesh copper grids (Plano, Wetzlar, Germany) in a cryo-specimen holder (Gatan, California, USA). A LEO 912 AB cryo-electron microscope (Zeiss, Oberkochen, Germany) operating at $-170^{\circ} \mathrm{C}$ with an accelerating voltage of $120 \mathrm{kV}$ was used for analysis. The 16-bit grayscale images were recorded on a 1,024 × 1,024 camera (ProScan, Lagerlechfeld, Germany).

Image analysis

All image analysis and processing routines were performed in ImageJ on the original 16-bit images. The lamellar periodicity was calculated from profile plots along a centripetal line of 15 pixels width (averaging 15 pixels). Distances are given as mean \pm standard deviation $(n=17)$.

The lamellae periodicity was corrected for compression induced by cryo-sectioning (Zuber et al. 2005). The binarization procedure was executed in ImageJ by auto-applying default threshold settings.

\section{Results}

Chemically fixed (Group A) and high-pressure frozen, freeze-substituted samples (Group B)

Judging from the absence of segregation artifacts at high magnification $(50,000 \times)$, uniformity of staining of the cytosol and the smooth appearance of membranes (see e.g., mitochondria: no irregularly corrugated or wavy borders), the quality of the high-pressure frozen/freeze-substituted lung tissue was acceptable (Fig. 1). Occasionally, optimally frozen areas of lung parenchyma were observed adjacent to segregated lung tissue (not shown). The lamellar bodies observed were surrounded by a smooth limiting membrane. Lamellae, both parallel and concentrically arranged, were tightly packed. Then again, clefts between the lamellae of the lamellar bodies were present (Fig. 1c), as is typical for chemically fixed, dehydrated and osmicated samples (Fig. 1d).

\section{Cryo-electron microscopy of vitreous sections (Group C)}

A vitreous section as seen in the cryo-electron microscope is shown in Fig. 2. Figure 2a displays an overview of the cell with nucleus, fine smooth membranes, most probably endoplasmic reticulum, and a group of darker lamellar bodies (see inset for help in interpretation). Knife marks, a 
Fig. 1 Comparison of highpressure frozen/freeze-substituted type II alveolar epithelial cells (Group B; a, c) with chemically fixed samples (Group A; b, d). The cryofixed samples show smooth membranes (LB, M). Burst mitochondria are absent. Weighted against the cytoplasm, the matrix of cryofixed/freeze-substituted mitochondria demonstrates more electron scattering events, resulting in a darker appearance; an indication of improved retention of material in these organelles. Cryofixed/freezesubstituted lamellar bodies (LB) seem similar to those treated by chemical fixation, including the presence of erratic fissures
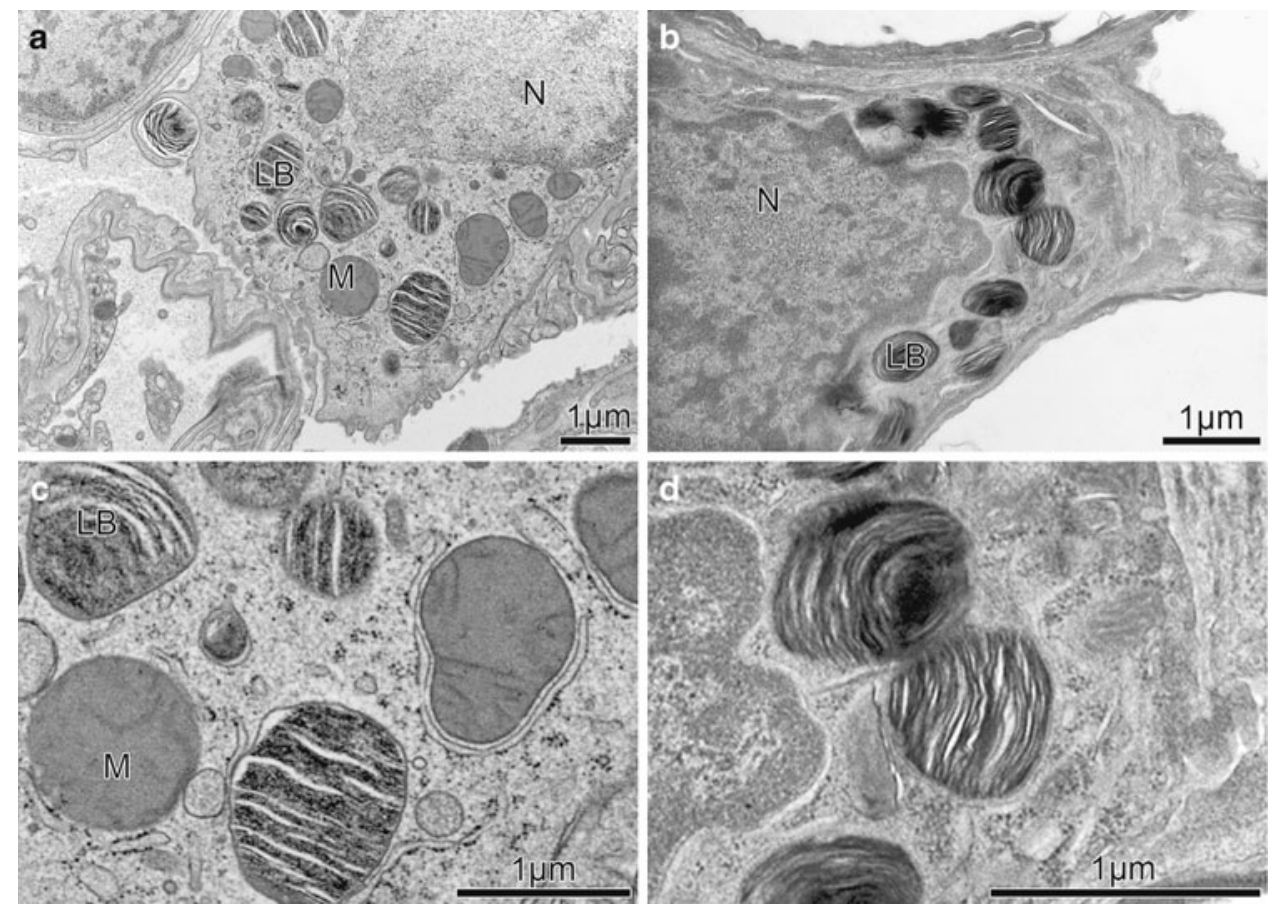

known artifact of this technique, are visible as horizontal lines. The edge of an ice crystal contamination induced during the sectioning process lies atop the section. The irregular pattern artifact throughout the section, perpendicular to the knife marks, is known as chatter and is due to change in the friction of the knife on the forming section (Al-Amoudi et al. 2005). A higher magnification of a lamellar body is shown in Fig. 2b. The lamellae of the lamellar bodies are periodically arranged and surrounded by a limiting membrane. A gap, characterized by a relatively low electron scattering content, exists at the luminal side of the limiting membrane (Fig. 2b, between the arrowheads) with an average width of $22.9 \pm 3.7 \mathrm{~nm}$. Although low scattering, the gap is not empty and filamentous structures cross the gap at irregular intervals (Fig. 2e). The limiting membrane, $17.5 \pm 3.3 \mathrm{~nm}$ wide, is more than twice as wide as the internal lamellae. The lamellae are periodically arranged and clefts, as seen in the osmium-treated samples, are absent. The average periodicity varied little and was calculated at $7.3 \pm 1.4 \mathrm{~nm}$. The pixel size of this image is $0.7 \mathrm{~nm}$. Figure $2 \mathrm{c}$ shows a profile plot depicted from a 15 pixel-wide centripetal line denoted in Fig. 2b. From right to left, the limiting membrane (1) is encountered first, which is seen as a decline in the grayscale, followed by the aforementioned electron-translucent gap (2), with a slight drop in grayscale at the middle, and finally a large number of cyclic undulations in grayscale values, representing the lamellae (3). Interestingly, positions were found where a lamella seemed to bifurcate into two lamellae (Fig. 2b, d). A higher magnification is shown in Fig. 2d, including a binarization inset with maximized contrast.

\section{Discussion}

The aim of the present study was to observe lamellar body ultrastructure without the use of chemical fixatives, dehydration, cryoprotection or heavy metal staining procedures.

The necessity to avoid chemical fixation immediately leads to cryofixation. This insight was made decades ago, also for lung tissue (Untersee et al. 1971). However, the need for a mild chemical fixation was often essential to obtain usable samples, counteracting factually all efforts put into the cryofixation procedure. Furthermore, the infiltration of cryoprotectants is a regular practice to avoid destructive ice crystal formation, which leads to specific artifacts accordingly. Glycerol is known to change the structure of lipid membranes and the clustering of intramembrane particles (Hayat 2000). Exactly these types of artifacts should be avoided when considering lamellar body ultrastructure. For completeness of the discussion, fixation by microwave heating should be considered. However, the use as fixation method is limited for general applications and if, then only in combination with aldehyde fixation (Hayat 2000).

The cryofixation techniques used (mostly plunge freezing) are ambient pressure based and are therefore limited to $20 \mu \mathrm{m}$ crystal-free fixation depth. The crystal-free fixation depth is reduced to $5 \mu \mathrm{m}$ for the (air-filled) lung (Lee and Bastacky 1995). High-pressure freezing implies a non-compressible sample as most water-based biological tissues are, but not the lung. Here, we present a workaround for the incompatibility of high-pressure freezing and air-filled lung tissue. 


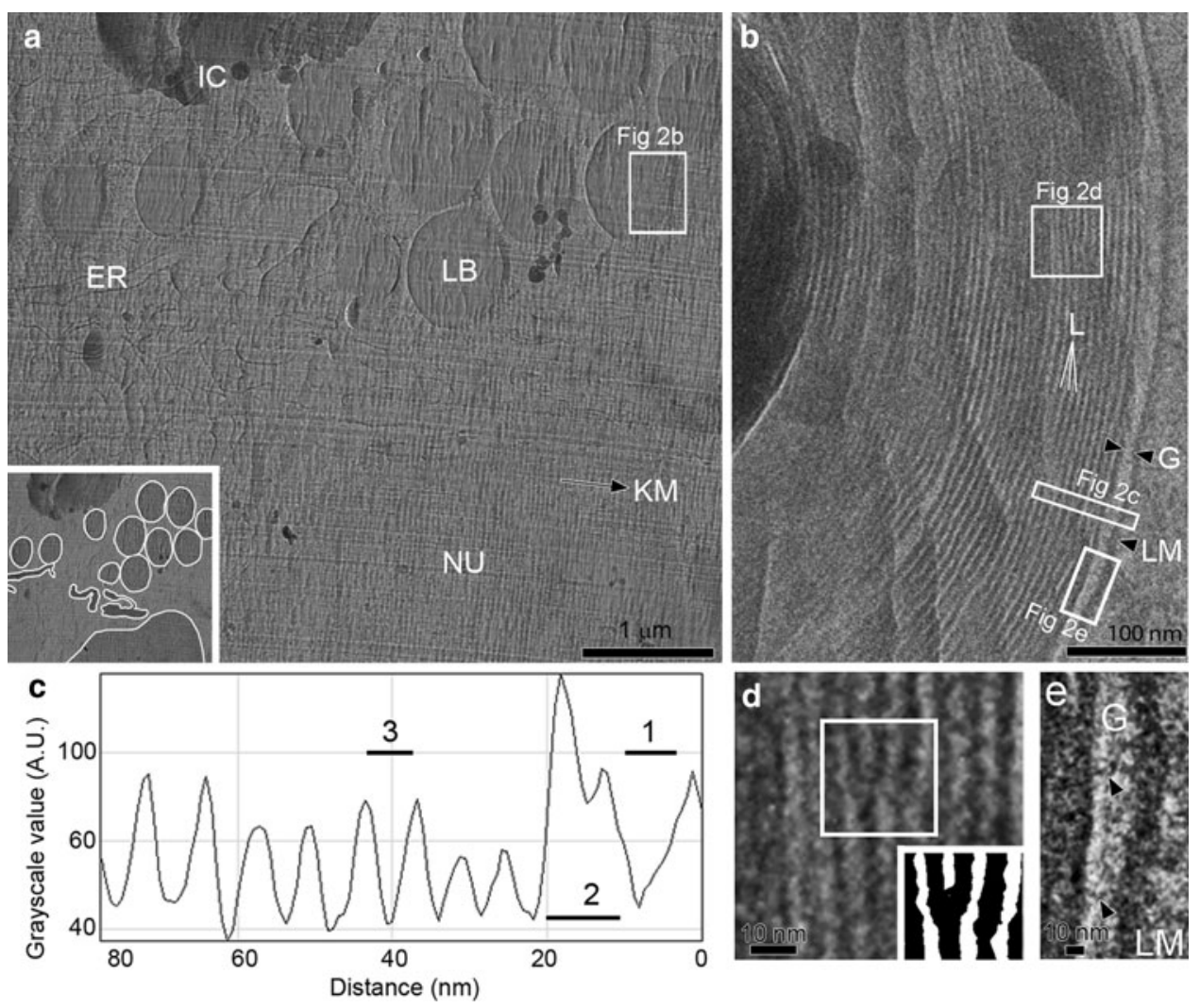

Fig. 2 Cryo-electron microscopy of vitreous sections (CEMOVIS) of rat lung. Part of a type II alveolar epithelial cell is shown in a. Because of the lack of contrasting agents, the contrast formation is produced by biological density only. The inset helps with the interpretation of the structures. Besides a nucleus (NU), a dense cytoplasm containing membranous structures, most probably endoplasmic reticulum (ER) and a cluster of lamellar bodies (LB) can be seen. An ice crystal (IC) is visible as dark spots. Knife marks (KM) run horizontally (arrow). b Details of an LB. The limiting membrane (LM) borders the LB. A relatively electron-translucent gap $(\mathrm{G})$ separates the LM from the concentric lamellae (L). c A profile plot of the peripheral region indicated

To date, perfluorocarbon-based liquid ventilation is the best studied substitution for conventional ventilation (Hirschl et al. 1995; Shaffer et al. 1992; Wolf et al. 2008). Perfluorocarbons are characterized by a high potential for gas transport (Fuhrman et al. 1991), chemical inertness (Rudiger et al. 2000) and low surface tension (Schurch et al. 1976). Furthermore, perfluorocarbons can be considered hydrostatic and non-compressible up to $1.2 \mathrm{GPa}$ (Varga et al. 2003), far above the operating pressure of 0.2 $\mathrm{GPa}$ of the high-pressure freezing device (Studer et al. 2001). Perfluorocarbons are therefore both physiologically and methodically suitable.

Despite the many advantages of perfluorocarbon ventilation and high-pressure freezing, artifacts will be introduced as well. Perfluorocarbons were found in liposomes and erythrocyte membranes (Obraztsov et al. 2000), signifying that perfluorocarbons gain access to the lipid component of cellular membranes. However, the rate of uptake was very in $\mathbf{b}$ is shown. From left to right, the limiting membrane (1), appears as a depression of grayscale values about $10 \mathrm{~nm}$ wide. The translucent gap (2), with a width of about $15 \mathrm{~nm}$ follows. The lamellae are represented in the profile plot as undulations (3), with a constant frequency of $7.3 \mathrm{~nm}$ in average. $\mathbf{d}$ Higher magnification of $\mathbf{b}$. The bifurcation of the lamellae is evident, especially in the inset showing a binarized analysis of the denoted area. e Higher magnification of $\mathbf{b}$ showing the electron-translucent gap (G) separating the limiting membrane (LM) from the concentric lamellae. The center of the gap exhibits a slightly higher electron scattering (arrowheads), which is also deducible from the drop in grayscale values at about $15 \mathrm{~nm}$ in the profile plot

slow; cells exposed for short intervals (minutes) did not have detectable perfluorocarbon content (Obraztsov et al. 2000). Increase of perfluorocarbon-mediated surfactant secretion and a decrease in phospholipid synthesis are effects shown as fast as 10 min after submerging alveolar epithelial type II cells in vitro (Rudiger et al. 2003). Interestingly, such effects were absent in vivo (Rudiger et al. 2007). An electron microscopic study found that short-term liquid ventilation neither affected the intracellular surfactant composition nor the surfactant content (Rudiger et al. 2007). Therefore, we assume that perfluorocarbon did not cause major structural alterations to the intracellular lamellar bodies and their lipid arrangement within the time period of the experiment ( $\sim 15 \mathrm{~min})$.

The impact of high pressure on biological material is still poorly understood and investigations of the effects refer mainly to pressure intervals in the range of seconds or minutes (Braganza and Worcester 1986), whereas, in the 
case of high-pressure freezing, the sample is exposed to hydrostatic pressure for only $600 \mathrm{~ms}$ at the most (Studer et al. 2001). Still, at subsecond timescale, pressuremediated alterations were observed, such as alterations in the macroripple structure of DPPC membranes during phase transition (Semmler et al. 1998), however, with the prerequisite that an unstable and stressed molecule packing configuration is present in the membrane. Deformations due to the pressure shockwave during high-pressure freezing can be neglected (Semmler et al. 1998).

The formation of artifacts cannot be avoided completely, but with the approach described here the induced artifacts are fundamentally different from the artifacts induced by chemical fixation, dehydration, cryoprotectants, osmication or embedding. The artifacts induced by these methods were completely absent in our samples. Therefore, we consider the perfluorocarbon/high-pressure freezing approach valuable: it delivers a new and alternative angle to the lamellar body ultrastructure.

By omitting chemical fixatives alone, one cannot explain the occurrence of clefts between the lamellae of lamellar bodies. This could also be derived from the fact that such clefts are seen in freeze-substituted samples (Fig. 1) and other freeze-substitution studies (Ikeda et al. 1984), as well as in freeze-dried studies (Yang et al. 2006). Thus, this artifact must be produced by dehydration, osmification or embedding procedures. Indeed, in an early attempt, mildly chemically fixed but hydrated and not osmicated sections showed no clefts (Kawanami and Lauweryns 1977). Furthermore, frozen hydrated sections of cryoprotected tissue (2.3 $\mathrm{M}$ sucrose) after mild chemical fixation, known as the Tokuyasu immunolabeling method, provide a weak but tightly packed lamellation without clefts (Walker et al. 1986; Liu et al. 1996). Attempts with Araldite embedding media were able to show chemically fixed lamellar bodies with minute clefts only when uranyl acetate was used for prolonged bloc staining (Fehrenbach 1991). In this study, bifurcations of the lamellae could be observed. As the existence of the bifurcations is confirmed in CEMOVIS samples, the possibility that these structures can be dismissed as artifacts becomes highly unlikely. Lamellar body biogenesis models must therefore be able to explain the formation of such ultrastructure. The possibility that the hydrophobic surfactant proteins SP-B and SP-C are involved in the formation of these bifurcations (see Perez-Gil 2008) should be addressed in future studies.

The contrast formation in CEMOVIS sections is fundamentally different from osmium-treated plastic sections. It reflects the distribution of biological material rather than binding sites of heavy metals. Although the cutting artifacts can be severe, they can always be related to the cutting direction and therefore be systematically recognized and thus taken into consideration. The periodicity of the lamellae is used as a measure for the retention of the lamellar body content and therefore structural quality (Stratton 1977). Biological significance is provided through precise functional models of intracellular lamellar bodies, which fit in data obtained from a variety of sources, such as physiological, biochemical and crystallographic data, as well as direct ultrastructural observations (Perez-Gil 2008). Bias on the ultrastructural component of the model could render correct interpretations of the other sources impossible. The analysis of the CEMOVIS sections in the present study provided a lamellar periodicity of $7.3 \mathrm{~nm}$. Previous analysis of the periodicity, involving chemical fixation and osmium treatment, resulted in lower periodicities: from $4.2 \mathrm{~nm}$ (Weibel et al. 1966) up to $6.6 \mathrm{~nm}$ (Stratton 1976, 1977). Freezedried tissue, cryofixed but osmificated, also produced periodicities of $4.2 \mathrm{~nm}$ (McAteer and Terracio 1984). In chemically fixed/freeze fractured tissue, and thus not osmificated, a lamellar body lamellae periodicity of $4-5.5 \mathrm{~nm}$ was found (Takemura et al. 1987). Osmium is known to induce variations in thickness of membranes: the hydrophobic layer increases in thickness, whereas the hydrophilic layers remain unchanged (Hayat 2000). In addition to variations in membrane thickness, osmium rapidly destroys the semipermeability of membranes as well. This osmium-induced swelling is to a certain extent counteracted by the anisotropic shrinkage during dehydration and plastic embedding (Hayat 2000). Furthermore, aldehyde fixation retains lipids to varying degrees (Glauert and Lewis 1998), and slow tissue penetration creates a methodological bias. Freeze-drying techniques have also been linked to shrinkage effects (Bastacky et al. 1995). We interpret that the generally lower periodicities are probably a combination of shrinkage/ swelling effects induced by the fixation and membrane alterations by the osmium treatment.

The approach of Bastacky et al. (1995) provided platinum-coated samples free of chemical fixatives, cryoprotectants, dehydration solvents and osmium treatment, but the tissue was ice crystal-free only up to a depth of $5 \mu \mathrm{m}$. The significance of this depth boundary is that only the flattened alveolar epithelial type I cells had a chance of being free of ice crystals, and not the much thicker lamellar body containing alveolar epithelial type II cells. Intracellular lamellar bodies in alveolar epithelial type II cells and the periodicity of their lamellae could not be assessed.

To our knowledge, this paper provides the first analysis of lamellae periodicity based on CEMOVIS. The analysis based on cryo-electron microscopy of frozen hydrated sections provided here delivers a periodicity, which is considerably higher than those found in literature. However, an early study attempting cryo-electron microscopy after a mild aldehyde fixation (but no dehydration, cryoprotecting or osmium treatment) also reported a higher lamellae periodicity of "about $80 \AA$ ” (Kawanami and Lauweryns 1977). 
As discussed, the methods used in the perfluorocarbon/ high-pressure freezing approach possess their own set of artifacts, but none affecting the osmolarity of intracellular lamellar bodies or causing swelling/shrinkage effects. Moreover, the contrast in the images is independent of staining techniques, so reflecting the biological distribution. It is therefore right to confer to lamellae periodicity, whereas osmiumstained tissue should be referred to as osmiophilic periodicity.

A low electron scattering area of about $22 \mathrm{~nm}$ wide, situated at the luminal side of the limiting membrane, is present in the frozen hydrated sections. Such a feature is absent in state-of-the-art ultrastructural data and models of lamellar bodies (Ochs 2010; Perez-Gil 2008). We presume that this gap is a physiological true entity, and not an artifact. The absence of this feature in literature might be a shrinkage artifact, provoked by shrinkage effects as discussed above.

In summary, our approach makes the surfactant system and the native cellular ultrastructure of the lung available for examination by cryo-electron microscopy of frozen hydrated sections, avoiding the use of chemical fixatives, dehydration, cryoprotection or heavy metal staining procedures. Therefore, this approach provides potential for scrutinizing various theories of lamellar body biogenesis, exocytosis and recycling.

Acknowledgments This study has been supported in part by grants from the Swiss National Science Foundation (SNF 3100AO-116417) to M.O. and (SNF 31003A-118394) to D.S. The experiments were performed according to the $3 \mathrm{R}$ principle and were approved by the cantonal administration of Bern, Switzerland for animal testing (38/09) to D.V.

\section{References}

Al-Amoudi A, Chang JJ, Leforestier A, McDowall A, Salamin LM, Norlen LPO, Richter K, Blanc NS, Studer D, Dubochet J (2004a) Cryo-electron microscopy of vitreous sections. EMBO J 23:3583-3588

Al-Amoudi A, Norlen LPO, Dubochet J (2004b) Cryo-electron microscopy of vitreous sections of native biological cells and tissues. J Struct Biol 148:131-135

Al-Amoudi A, Studer D, Dubochet J (2005) Cutting artefacts and cutting process in vitreous sections for cryo-electron microscopy. J Struct Biol 150:109-121

Askin FB, Kuhn C (1971) The cellular origin of pulmonary surfactant. Lab Invest 25:260-268

Bastacky J, Lee CYC, Goerke J, Koushafar H, Yager D, Kenaga L, Speed TP, Chen Y, Clements JA (1995) Alveolar lining layer is thin and continuous-low-temperature scanning electron-microscopy of rat lung. J Appl Physiol 79:1615-1628

Braganza LF, Worcester DL (1986) Structural changes in lipid bilayers and biological membranes caused by hydrostatic pressure. Biochemistry 25:7484-7488

Clements JA (1997) Lung surfactant: a personal perspective. Annu Rev Physiol 59:1-21

Collet AJ (1979) Preservation of alveolar type-II pneumocyte lamellar bodies for electron-microscopic studies. J Histochem Cytochem 27:989-996
Costello MJ, Gulikkrzywicki T (1976) Correlated X-ray diffraction and freeze-fracture studies on membrane model systems perturbations induced by freeze-fracture preparative procedures. Biochim Biophys Acta 455:412-432

Douglas W, Redding R, Stein M (1975) The lamellar substructure of osmiophilic inclusion bodies present in rat type II alveolar pneumonocytes. Tissue Cell 7:137-142

Dubochet J, Adrian M, Chang JJ, Homo JC, Lepault J, McDowall AW, Schultz P (1988) Cryo-electron microscopy of vitrified specimens. Q Rev Biophys 21:129-228

Dubochet J, Zuber B, Eltsov M, Bouchet-Marquis C, Al-Amoudi A, Livolant F (2007) How to "read" a vitreous section. Cell Electron Microsc 79:385-406

Escaig J (1982) New instruments which facilitate rapid freezing at $83 \mathrm{~K}$ and $6 \mathrm{~K}$. J Microsc 126:221-229

Fehrenbach H (1991) Improved preservation of phopholipid-rich multilamellar bodies in conventionally embedded mammalian lungtissue - an electron spectroscopic study. J Microsc 162(1):91-104

Fehrenbach H (2001) Alveolar epithelial type II cell: defender of the alveolus revisited. Respir Res 2:33-46

Fehrenbach H, Ochs M (1998) Studying lung structure. In: Uhlig S, Taylor AE (eds) Methods in pulmonary research. Birkhäuser, Basel, pp 429-454

Fuhrman BP, Paczan PR, Defrancisis M (1991) Perfluorocarbon-associated gas-exchange. Crit Care Med 19:712-722

Glauert A, Lewis P (1998) Biological specimen preparation for transmission electron microscopy. In: Glauert A (ed) Practical methods in electron microscopy, vol 17. Portland Press, London, p 326

Hayat M (2000) Principles and techniques of electron microscopy: biological applications. Cambridge University Press, Cambridge, UK

Hirschl RB, Pranikoff T, Gauger P, Schreiner RJ, Dechert R, Bartlett RH (1995) Liquid ventilation in adults, children, and full-term neonates. Lancet 346:1201-1202

Ikeda H, Ichikawa A, Ichikawa M (1984) The effects of freeze-substitution media on the ultrastructure of inclusion-bodies in type-II pneumocytes of mouse lung processed by the cryofixation method. J Electron Microsc 33:242-247

Kawanami O, Lauweryns JM (1977) Observation of ultrastructure of lung-tissue with negative stain in cryo-ultramicrotomy. Acta Histochemica et Cytochemica 10:271-279

Kikkawa Y, Manabe T (1978) Freeze-fracture study of alveolar type-II cells and alveolar content in fetal rabbit lung. Anat Rec 190:627-637

Kikkawa Y, Motoyama EK, Cook CD (1965) The ultrastructure of the lungs of lamb. The relation of osmiophilic inclusions and alveolar lining layer to fetal maturation and experimentally produced respiratory distress. Am J Pathol 47:877-903

Kuhn C (1968) Cytochemistry of pulmonary alveolar epithelial cells. Am J Pathol 53:809-833

Lee CY, Bastacky J (1995) Comparative mathematical analyses of freezing in lung and solid tissue. Cryobiology 32:299-305

Liu W, Geuze HJ, Slot JW (1996) Improving structural integrity of cryosections for immunogold labeling. Histochem Cell Biol 106:41-58

Mason RJ, Williams MC (1977) Type-2 alveolar cell—defender of alveolus. Am Rev Respir Dis 115:81-91

McAteer JA, Terracio L (1984) Pulmonary type-II cell lamellar body ultrastructure preserved by rapid freezing and freeze-drying. Anat Rec 209:355-362

Muhlfeld C, Rothen-Rutishauser B, Vanhecke D, Blank F, Gehr P, Ochs M (2007) Visualization and quantitative analysis of nanoparticles in the respiratory tract by transmission electron microscopy. Part Fibre Toxicol 4(11):1-17

Niedermeyer W, Parish GR, Moor H (1977) Reactions of yeast cells to glycerol treatment-alterations to membrane structure and glycerol uptake. Protoplasma 92:177-193 
Obraztsov VV, Neslund CG, Kornbrust ES, Flaim SF, Woods CM (2000) In vitro cellular effects of perfluorochemicals correlate with their lipid solubility. Am J Physiol Lung Cell Mol Phys 278:L1018-L1024

Ochs M (2010) The closer we look the more we see? Quantitative microscopic analysis of the pulmonary surfactant system. Cell Physiol Biochem 25:27-40

Ochs M, Knudsen L, Allen L, Stumbaugh A, Levitt S, Nyengaard JR, Hawgood S (2004) GM-CSF mediates alveolar epithelial type II cell changes, but not emphysema-like pathology, in SP-D-deficient mice. Am J Physiol Lung Cell Mol Physiol 287:L1333L1341

Perez-Gil J (2008) Structure of pulmonary surfactant membranes and films: the role of proteins and lipid-protein interactions. Biochimica Et Biophysica Acta-Biomembranes 1778:1676-1695

Richter K (1994) A cryoglue to mount vitreous biological specimens for cryoultramicrotomy at $110 \mathrm{~K}$. J Microsc 173:143-147

Rudiger S, Gross U, Kemnitz E (2000) Perfluorocarbons: useful tools for medicine. Eur J Med Res 5:209-216

Rudiger M, Wissel H, Ochs M, Burkhardt W, Proquitte H, Wauer RR, Stevens P, Rustow B (2003) Perfluorocarbons are taken up by isolated type II pneumocytes and influence its lipid synthesis and secretion. Crit Care Med 31:1190-1196

Rudiger M, Wendt S, Kothe L, Burkhardt W, Wauer RR, Ochs M (2007) Alterations of alveolar type II cells and intraalveolar surfactant after bronchoalveolar lavage and perfluorocarbon ventilation. An electron microscopical and stereological study in the rat lung. Respir Res 8(40):1-9

Sartori N, Richter K, Dubochet J (1993) Vitrification depth can be increased more than 10-fold by high-pressure freezing. J Microsc 172:55-61

Schulz WW, McAnalley WH, Reynolds RC (1980) Freeze-fracture study of pulmonary lamellar body membranes in solid crystal phase. J Ultrastruct Res 71:37-48

Schurch S, Goerke J, Clements JA (1976) Direct determination of surface tension in lung. Proc Natl Acad Sci USA 73:4698-4702

Semmler K, Wunderlich J, Richter W, Meyer HW (1998) High-pressure freezing causes structural alterations in phospholipid model membranes. J Microsc 190:317-327

Shaffer TH, Wolfson MR, Clark LC (1992) Liquid ventilation. Pediatr Pulmonol 14:102-109

Shimoni E, Muller M (1998) On optimizing high-pressure freezing: from heat transfer theory to a new microbiopsy device. J Microsc 192:236-247

Smith DS, Smith U, Ryan JW (1972) Freeze-fractured lamellar body membranes of rat lung great alveolar cell. Tissue Cell 4:457-468

Sorokin SP (1967) A morphologic and cytochemical study on the great alveolar cell. J Histochem Cytochem 14:884-897

Stratton CJ (1976) High-resolution ultrastructure of periodicity and architecture of lipid-retained and extracted lung multilamellar body laminations. Tissue Cell 8:713-728

Stratton CJ (1977) Periodicity and architecture of lipid retained and extracted lung surfactant and its origin from multilamellar bodies. Tissue Cell 9:301-316

Studer D, Michel M, Wohlwend M, Hunziker EB, Buschmann MD (1995) Vitrification of articular cartilage by high-pressure freezing. J Microsc 179:321-332
Studer D, Graber W, Al-Amoudi A, Eggli P (2001) A new approach for cryofixation by high-pressure freezing. J Microsc 203:285-294

Takemura T, Fukuda Y, Harrison M, Ferrans VJ (1987) Ultrastructural, histochemical, and freeze-fracture evaluation of multilamellated structures in human pulmonary alveolar proteinosis. Am J Anat 179:258-268

Terracio L, Bankston PW, McAteer JA (1981) Ultrastructural observations on tissues processed by a quick-freezing, rapid-drying method-comparison with conventional specimen preparation. Cryobiology 18:55-71

Untersee P, Gil J, Weibel ER (1971) Visualization of extracellular lining layer of lung alveoli by freeze-etching. Respir Physiol 13:171-185

Vanhecke D, Graber W, Herrmann G, Al-Amoudi A, Eggli P, Studer D (2003) A rapid microbiopsy system to improve the preservation of biological samples prior to high-pressure freezing. J Microsc 212:3-12

Vanhecke D, Eggli P, Graber W, Studer D (2006) A new microbiopsy system enables rapid preparation of tissue for high-pressure freezing. Methods Mol Med, pp 463-477

Varga T, Wilkinson AP, Angel RJ (2003) Fluorinert as a pressuretransmitting medium for high-pressure diffraction studies. Rev Sci Instrum 74:4564-4566

Walker SR, Williams MC, Benson B (1986) Immunocytochemical localization of the major surfactant apoproteins in type-II cells, clara cells, and alveolar macrophages of rat lung. J Histochem Cytochem 34:1137-1148

Weaver TE, Na CL, Stahlman M (2002) Biogenesis of lamellar bodies, lysosome-related organelles involved in storage and secretion of pulmonary surfactant. Seminars Cell Dev Biol 13:263-270

Weibel ER, Kistler GS, Tondury G (1966) A stereologic electron microscope study of tubular myelin figures in alveolar fluids of rat lungs. Zeitschrift für Zellforschung und Mikroskopische Anatomie 69:418-427

Williams MC (1978) Freeze-fracture studies of tubular myelin and lamellar bodies in fetal and adult rat lungs. J Ultrastruct Res 64:352-361

Willison M, Rowe A (1980) Replica, shadowing and freeze-etching techniques. Freeze-fracturing and freeze-etching. North-Holland Publishing Company, Amsterdam, p 301

Wolf GK, Sheeran P, Heitz D, Thompson JE, Arnold JH (2008) Gas exchange and lung mechanics during high frequency ventilation in the perflubron-treated lung. Pediatr Crit Care Med 9:641-646

Wright JR (1997) Immunomodulatory functions of surfactant. Physiol Rev 77:931-962

Wright JR (2005) Immunoregulatory functions of surfactant proteins. Nat Rev Immunol 5:58-68

Wright TW, Notter RH, Wang ZD, Harmsen AG, Gigliotti F (2001) Pulmonary inflammation disrupts surfactant function during Pneumocystis carinii pneumonia. Infect Immun 69:758-764

Yang CL, Terada N, Ohno N, Fujii Y, Ohno S (2006) Morphological analysis of lamellar structures in mouse type II pneumocytes by quick-freezing and freeze-drying with osmium tetroxide vaporfixation. Med Mol Morphol 39:88-96

Zuber B, Nikonenko I, Klauser P, Muller D, Dubochet J (2005) The mammalian central nervous synaptic cleft contains a high density of periodically organized complexes. Proc Natl Acad Sci USA 102:19192-19197 